\begin{tabular}{cc|c}
\hline Tar. Bil. Der. & Journal of Agricultural Sciences \\
& $\begin{array}{c}\text { Dergi web sayfası: } \\
\text { www.agri.ankara.edu.tr/dergi }\end{array}$ & Journal homepage: \\
& www.agri.ankara.edu.tr/journal
\end{tabular}

\title{
Farklı Tuz Stresi Altındaki Domates Bitkisinin Spektral Yansıma İlişkileri
}

\author{
Namık Kemal SÖNMEZ ${ }^{a}$, Gülçin Ece ASLAN ${ }^{b}$, Ahmet KURUNÇ \\ ${ }^{a}$ Akdeniz Üniversitesi, Fen Fakültesi, Uzay Bilimleri ve Teknolojileri Bölümü, Antalya, TURKEY

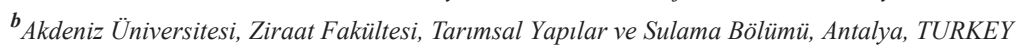

\section{ESER BİGISİ}

Araştırma Makalesi

DOI: 10.1501/Tarimbil_0000001359

Sorumlu Yazar: Namık Kemal SÖNMEZ, E-posta: nksonmez@akdeniz.edu.tr, Tel: +90 (532) 3948469

Geliş Tarihi: 13 Şubat 2014, Düzeltmelerin Gelişi: 25 Ekim 2014, Kabul: 12 Kasım 2014

\begin{abstract}
ÖZET
$\mathrm{Bu}$ çalışmada farklı tuzluluk düzeyine sahip sulama sularının domates bitkisinin enerji kullanımı üzerine etkileri incelenmiştir. Deneme, tesadüf parselleri deneme desenine göre ve kontrollü sera ortamında saksı denemesi şeklinde gerçekleştirilmiştir. Denemede bitki yetiştirme periyodu süresince domates bitkisine kontrol konusuna $\left(0.5 \mathrm{dS} \mathrm{m}^{-1}\right) \mathrm{ek}$ olarak dört farklı tuzluluk düzeyine $\left(1.5 \mathrm{dS} \mathrm{m}^{-1}, 2.2 \mathrm{dS} \mathrm{m}^{-1}, 3.4 \mathrm{dS} \mathrm{m}^{-1}, 5.8 \mathrm{dS} \mathrm{m}^{-1}\right)$ sahip sulama suyu uygulamas1 yapılmıştır. Bu süreçte, elektromanyetik spektrumun 330-1075 nm aralığında algılama yapan el spektroradyometresi ile her bir deneme konusu için spektral ölçümler gerçekleştilmiştir. Çalışmada ayrıca, Bitki İndeks Oranı (VI), Normalize Edilmiş Bitki İndeksi (NDVI), Tuzluluk İndeksi (SI) ve Normalize Edilmiş Tuzluluk İndeksi (NDSI) hesaplamaları da yapılmıştır. Deneme sonucunda yapılan istatistiksel analizlerde, tuz stresinin belirlenmesinde bitkinin yansıma değerleri ile hesaplanan indeks değerleri arasında önemli ilişkiler bulunmuştur. Araştırma sonucunda domates bitkisinde tuzluluktan kaynaklanan bitki stres koşularının, mavi ve kırmızı dalga boyunda bitki gelişim periyodunun 16. haftasında, yeşil dalga boyu bölgesinde ise 13. haftasında ortaya çıktığı belirlenebilmiştir. Hesaplanan VI değeri gelişim periyodunun 12. haftasında, NDVI değerleri 14. haftasında, SI değerleri 16. haftasında, NDSI hesaplaması ise 14. haftasında belirleyici olmuştur.
\end{abstract}

Anahtar Kelimeler: Uzaktan algılama; Domates; Spektroradyometre; Sulama suyu tuzluluğu

\section{Relationship Spectral Reflectance under Different Salt Stress Conditions of Tomato}

\author{
ARTICLE INFO \\ Research Article \\ Corresponding Author: Namık Kemal SÖNMEZ, E-mail: nksonmez@akdeniz.edu.tr, Tel: +90 (532) 3948469 \\ Received: 13 February 2014, Received in Revised Form: 25 October 2014, Accepted: 12 November 2014
}

\footnotetext{
ABSTRACT

This study was conducted to investigate effect of irrigation water salinity on energy usage of tomato plant. The experiment was carried out in a completely randomized design under controlled greenhouse environment as a pot experiment.
} 
In addition to kontrol $\left(\mathrm{S}_{0}=0.5 \mathrm{dS} \mathrm{m} \mathrm{m}^{-1}\right)$ treatment, four different levels of saline irrigation water $\left(\mathrm{S}_{1}=1.5, \mathrm{~S}_{2}=2.2, \mathrm{~S}_{3}=3.4\right.$, $\mathrm{S}_{4}=5.8 \mathrm{dS} \mathrm{m}^{-1}$ ) were applied to tomato during growing period. Spectral measurements were made for each trial subject with handheld spectroradiometer which has a detection between 330-1075 nanometers wavelength interval. Furthermore, Vegetation Index (VI), Normalized Difference Vegetation Index (NDVI), Normalized Difference Salinity Index (NDSI) and Salinity Index (SI) values were calculated. Considering statistical analysis, significant relationship were found between plant reflectance and calculated index values in detecting salt stress. In conclusion, plant stres conditions caused by salinity on tomato was started in $16^{\text {th }}$ weeks of plant growing period for the blue and red wavelengths and in $13^{\text {th }}$ weeks for the green. Calculated VI, NDVI, SI and NDSI values were decisived in $12^{\text {th }}, 14^{\text {th }}, 16^{\text {th }}$ and $14^{\text {th }}$ weeks of plant growing period, respectively.

Keywords: Remote sensing; Tomato; Spectroradiometer; Irrigation water salinity

(C) Ankara Üniversitesi Ziraat Fakültesi

\section{Giriş}

Sulama suyu olarak kullanılan su kaynaklarının kalitelerindeki azalmaya bağlı olarak ortaya çıkan toprak tuzluluğunun bitkilere iki farklı önemli etkisi bulunmaktadır. Bunlardan ilki su alımını engelleyen toplam tuz etkisi veya ozmotik etki, diğeri ise bitkideki fizyolojik olayları etkileyen toksik iyon etkisidir (Bresler \& Charter 1982; James et al 1982). Toprakta yeterli su bulunmasına rağmen bitkinin suyu alamaması ve solmaya başlaması ozmotik etkinin en önemli göstergesidir. Buna fizyolojik kuraklık da denilmektedir (Ayyıldız 1990). Bu etkilerin sonucunda hormonal dengede yıkım meydana gelmekte, fotosentez azalmakta, nitrat alımının düşmesi nedeniyle de protein sentezinde azalma görülmekte ve bitki boyu kısalmaktadır. $\mathrm{Bu}$ durum, bitkinin yaş ve kuru ağırlığını etkilediğinden çiçek sayısının ve dolayısıyla da verimin azalmasına neden olmaktadır (Sharma 1980; Robinson et al 1983; Çakırlar \& Topçuoğlu 1985).

Bitkilerde düşük sulama suyu kalitesinden kaynaklanan bu etkilerin ortaya konulmasında günümüzde yeni teknik ve teknolojilerden yararlanılmaktadır. $\mathrm{Bu}$ teknolojilerden biri de uzaktan algılama bilimi ve teknolojisidir (Jackson 1984). Bu sistem, güneşten çıkarak yeryüzüne ulaşan elektromanyetik dalgaların yüzeydeki farklı nesnelere verdiği tepkilerin belirlenmesi esasına dayanmaktadır. Söz konusu teknoloji ile, havadan uçaklar ve uydular kullanılarak veya tarla düzeyinde spektroradyometre adı verilen araçlarla bitkilerin gelişme durumları, stres koşullarının izlenmesi mümkün olabilmektedir (Köksal 2007).

Uzaktan algılama çalışmalarında temel unsur, bitkilerin elektromanyetik spektruma verdikleri tepkinin belirlenmesidir. Bitkiler, spektrumun farklı dalga boyu bölgelerinde farklı absorbsiyon ve yansıtma özellikleri gösterirler (Merzlyak et al 2003). Bitki yaprakları görünür bölgede özellikle mavi ve kırmızı dalga boyu aralığında düşük yansıma gösterirken, görünür bölgenin son sınır1 olan kırmızı dalga boyu aralığından yakın kızıl ötesi dalga boyu aralığına geçildiğinde yansımada hızlı bir artış şeklinde kendini göstermektedir. Bitkilerden elde edilen en yüksek yansıma değerleri, yakın kızılötesi olarak ifade edilen dalga boylarında ortaya çıkmakta ve bitkinin birçok özelliği bu dalga boylarındaki farklılıklarla belirlenebilmektedir. $\mathrm{Bu}$ nedenle bitkisel üretimde uzaktan algılama çalışmaları daha çok yakın kızılötesi bölgede yoğunlaşmıştır (Jacquemoud \& Ustin 2001). Yersel uzaktan algılama ölçümleri olarak da adlandırılan spektroradyometrik ölçümlerle, bitki stres koşullarının belirlenmesi ve izlenmesi ile ilgili çalışmalar uzun yıllardan beri yapılmaktadır (Rahman et al 1994; White 1998).

$\mathrm{Bu}$ çalışmada, Antalya ilinde yaygın olarak üretimi yapılan domates bitkisinde farklı tuzluluk konsantrasyonlarına sahip sulama suyu uygulamalarından kaynaklanan stres koşullarının, elektromanyetik spektrumun farklı dalga boyu bölgelerinde yapılan spektroradyometrik ölçümlerle belirlenebilirliği ortaya konulmaya 
çalış1lmıştır. Bu kapsamda, farklı tuzluluk stresi koşullarında yetiştirilen domates bitkisinde, üretim periyodu boyunca, elektromanyetik spektrumun 330-1075 nanometre dalga boyları aralığında spektroradyometrik ölçümler yapılmış ve elde edilen veriler değerlendirilmiştir.

\section{Materyal ve Yöntem}

\subsection{Materyal}

Çalışmada farklı tuz konsantrasyonlarına sahip sulama sularıyla yetiştirilen domates bitkisinin, eletromanyetik spektrumun farklı dalga boyu bölgelerinde verdikleri tepkinin belirlenebilmesi hedeflenmiştir. $\mathrm{Bu}$ amaçla, bölgede yaygın üretim desenine sahip ve sonbahar örtü altı yetiştiriciliğine uygun olan Allegro F1 domates çeşidi materyal olarak kullanılmıştır. Deneme kontrollü sera ortamında $15 \mathrm{~kg}$ hava kurusu toprak alan saksılar içerisinde yürütülmüş ve her saksıya bir bitki dikilmiştir. Sera toprakları 4 mm'lik elekten elendikten sonra saksılara tartılarak konulmuştur. Denemede kontrol ile birlikte sulama suyu tuzluluk konusu olarak 5 farkl1 tuzlu su (Kontrol- $\mathrm{S}_{0}=$ $0.5 \mathrm{dS} \mathrm{m}^{-1}, \mathrm{~S}_{1}=1.5 \mathrm{dS} \mathrm{m}^{-1}, \mathrm{~S}_{2}=2.2 \mathrm{dS} \mathrm{m}^{-1}, \mathrm{~S}_{3}=$ $3.4 \mathrm{dS} \mathrm{m}^{-1}$ ve $\mathrm{S}_{4}=5.8 \mathrm{dS} \mathrm{m}^{-1}$ ) kullanılmış ve her bir konu $5 \mathrm{kez}$ tekrarlanmıştır. Tuzlu suların hazırlanmasında $\mathrm{CaCl}_{2}, \mathrm{MgSO}_{4}$ ve $\mathrm{NaCl}$ tuzlarından yararlanılmıştır. Tuzluluk dişında sodyumun toprak ve bitkiye direk veya dolaylı etkisini elimine etmek amaciyla sular, sodyum adsorpsiyon oranı (SAR) değerleri $<5$ ve $\mathrm{Ca} / \mathrm{Mg}$ oranı $1 / 1$ (meq l$^{-1}$ ) olacak şekilde hazırlanmıştır. Hedeflenen elektriksel iletkenlik değerlerini sağlamak için her bir tuzdan karıştırılması gerekli miktar hesaplandıktan sonra laboratuarda sulama sularının elektriksel iletkenlik (ECi) değerleri kontrol edilmiş ve gerekli düzeltmeler yapılarak denemede kullanıma hazır hale getirilmiştir. Kontrol konusu olarak $\mathrm{S}_{0}=0.5 \mathrm{dS}$ $\mathrm{m}^{-1}$ olan şebeke suyu kullanılmıştır. Hazırlanan sular 100 litre hacminde kapaklı plastik kaplar içerisinde muhafaza edilmiştir.

Domates bitkisi için gelişim periyodu boyunca spektroradyometrik ölçümler ASD Field Spect
Handheld spektroradyometresi ve plant probe kullanılarak gerçekleştirilmiştir.

\subsection{Yöntem}

Deneme başlangıcında deneme toprağının fiziksel ve kimyasal analizleri yapılmıştır (Çizelge 1).

Çizelge 1- Deneme toprağının bazı fiziksel ve kimyasal özellikleri

Table 1-Some physical and chemical properties of soil

\begin{tabular}{ll} 
Toprak tanecik dağılımı & \\
Kum (\%) & 25.0 \\
Silt (\%) & 32.0 \\
Kil (\%) & 43.0 \\
Toprak nem içeriği (\%) & 21 \\
Tarla kapasitesi (\%) & 28.7 \\
Solma noktası (\%) & 17.2 \\
Hacim ağırlığ $\left(\mathrm{g} \mathrm{cm}^{-3}\right)$ & 1.32 \\
Elektriksel iletkenlik $(1: 2.5)\left(\mathrm{dS} \mathrm{m}^{-1}\right)$ & 0.2 \\
pH $(1: 2.5)$ & 8.62 \\
\hline
\end{tabular}

Deneme boyunca saksı topraklarının nem içerikleri, deneme başlangıcında gravimetrik yöntemle kalibre edilmiş, teta prob yardımıyla gözlemlenmiş ve elverişli nemin \% 60-70'i tüketildiğinde sulamalar gerçekleştirilmiştir (FAO 1979). Ayrıca sulama uygulamasından önce ve sonra tansiyometre okumaları yapılmıştır. Saksı topraklarında her konuya ait tuzluluk artışını stabil hale getirmek amaciyla Ayers \& Westcot (1989) tarafından önerilen \% 15'lik yıkama oranı dikkate alınmıştır.

Uzaktan algılama çalışmalarında yersel ölçümleme teknikleri olarak adlandırılan spektroradyometrik ölçümler bitkiyi en iyi temsil eden yapraklarda fide tutum döneminden hasat sonuna kadar haftada 1 defa olmak üzere, 21 haftalık dönem boyunca gerçekleştirilmiştir. Spektroradyometrik ölçümler, 330-1075 nm dalga boyu gibi geniş bir ölçüm aralığı içerdiğinden, veri karmaşasına neden olmamak ve bitkinin farklı tuzluluk streslerinde değişik dalga boylarındaki 
enerji kullanım durumunu ortaya koyabilmek amaciyla, elektromanyetik spektrumun mavi (450-500 nm), yeşil (501-570 nm), kırmızı $(610-700 \mathrm{~nm})$ ve yakın kızılötesi (701-1075) dalga boyu aralıklarında ayrı ayrı incelenmiştir (Campbell 2006; CRISP 2011). Çalışmada ayrıca, spektroradyometrik ölçümler sonucu elde edilen veriler, aşağıda tanımlamaları yapılan farklı bitki indeksi değerlerine göre yorumlanmıştır.

Bant oranlama indeksi (VI); bitki indeksinin en basit şeklidir. Bant oranları, iki spektral bant arasında tersine ilişki olduğunda bazı gizli bilgilerin ortaya çıkmasını sağlamaktadır. Bu oranlama yöntemi ile bitki örtüsünün genel sağlığ1, toplam biyokütle, klorofil içeriği, arazi yüzeyini kaplayan vejetasyonun oranı gibi vejetasyon karakteristiklerini değerlendirmek için kullanılmaktadır. Bant oranlama indeksi Eşitlik 1'de verilmiştir (CCRS 2003).

$$
\mathrm{VI}=\mathrm{NIR} / \mathrm{R}
$$

Burada; NIR, yakın kızılötesi dalga boyu; R, kırmızı dalga boyu değerleridir.

Normalize edilmiş bitki indeksi (NDVI):Yakın kızılötesi ve görünür kırmızı dalga boyları arasındaki zıtlığı artırmak veya iki dalga boyundaki bilgiyi toplayarak, bitki varlığını incelemek üzere normalize edilmiş bitki indeksi oluşturulmuştur (NASA 2003). $\mathrm{Bu}$ indeks Eşitlik 2' de ifade edilmiştir.

$$
\mathrm{NDVI}=(\mathrm{NIR}-\mathrm{R}) /(\mathrm{NIR}+\mathrm{R})
$$

Tuzluluk İndeksi (SI) ve Normalize Edilmiş Tuzluluk İndeksi (NDSI): Tuzlu alanları ortaya çıkarmak ve sağlıklı bitki örtüsü ile bu katmanlardaki ilişkileri ortaya çıkarmak amacıyla tuzluluk indeksi (SI) ve normalize edilmiş tuzluluk indeksleri (NDSI) geliştirilmiştir. Bu indeksler Eşitlik 3 ve 4'de verilmiştir.

$$
\begin{aligned}
& \mathrm{SI}=\sqrt{B 1 \times B 2} \\
& \mathrm{NDSI}=(\mathrm{B} 3-\mathrm{B} 4) /(\mathrm{B} 3+\mathrm{B} 4)
\end{aligned}
$$

Burada; B1, mavi dalga boyunu; B2, yeşil dalga boyunu; B3, kırmızı dalga boyunu; B4, ise yakın kızılötesi dalga boylarını tanımlamaktadır (Khan \& Sato 2001).
Yukarıda kısaca açıklanan indeks değerleri istatistiksel olarak analiz edilmiş olup, varyans analizlerinde Minitab 13.1 paket programı kullanılmıştır. Ayrıca her bir özelliğe ait ortalama değerler MSTAT-C istatistik analiz programı yardımıyla değerlendirilmiştir.

\section{Bulgular ve Tartışma}

Mavi, yeşil, kırmızı ve yakın kızılötesi dalga boyları ile NDVI, VI, SI ve NDSI değerlerine ilişkin varyans analiz sonuçları tuzluluk stresi, dönem ve tuzluluk stresi X dönem için Çizelge 2'de sunulmuştur.

\section{Çizelge 2- Denemeye iliş kin varyans analiz sonuçları}

Table 2-Variation analysis results

\begin{tabular}{lccc}
\hline Dalga boyu/indeks & \multicolumn{3}{c}{$P>F$} \\
Tuzluluk & Dönem & $\begin{array}{c}\text { Tuzlulukx } \\
\text { Dönem }\end{array}$ \\
\hline Mavi dalga boyu & $* *$ & $* *$ & $* *$ \\
Yeşil dalga boyu & $* *$ & $* *$ & $* *$ \\
Kirmızı dalga boyu & $*$ & $* *$ & $* *$ \\
Yakın kızılötesi dalga boyu & $*$ & $* *$ & ns \\
VI & $* *$ & $* *$ & $* *$ \\
NDVI & $* *$ & $* *$ & $* *$ \\
SI & $* *$ & $* *$ & $* *$ \\
NDSI & $* *$ & $* *$ & $* *$ \\
\hline
\end{tabular}

**, \% 1 düzeyinde önemli; *, \% 5 düzeyinde önemli; ns, önemli değil; VI, bitki indeksi; NDVI, normalize edilmiş bitki indeksi; SI, tuzluluk indeksi; NDSI, normalize edilmiş tuzluluk indeksi

Elde edilen bulgulara göre, tuzluluk stresindeki artışlara bağlı olarak bitki yapraklarında yansımalarda artışlar meydana gelmiş vetuzluluk stresi uygulamaları ile spektrumun mavi, yeşil ve kırmızı dalgaboyları arasında \% 1 ve yakın kızılötesi dalga boyu arasında ise \% 5 düzeyinde önemli istatistiksel farklılıklar belirlenmiştir (Çizelge 2).

Elektromanyetik spektrumun mavi ve kırmızı dalga boyu bölgeleri klorofil absorbsiyon bölgeleri olup, bu bölgedeki absorbsiyon miktarı yani enerji kullanım düzeyi klorofil-a, klorofil-b ve karotenoid pigmentleri tarafindan kontrol edilmektedir. (Fillela \& Penuelas 1994; Merzlyak et al 2003). Nitekim, 
Maktav \& Sunar (1991), bitki stres durumunda bitki yapraklarındaki klorofil miktarının azalmasına bağlı olarak görünür bölgede, özellikle mavi ve kırmızı dalga boylarında yansımanın artış eğiliminde olduğunu ifade etmişlerdir. Rees (1990); Büker et al (1992) ve Filella \& Penuelas (1994) gibi pek çok araştırmacı da benzer ifadelerde bulunmuşlardır.

Çalışmada bitki yetiştirme periyodu boyunca spektrumun mavi dalga boyu bölgesinde elde edilen spektral değerler ile uygulamalar arasındaki ilişkiler istatistiksel olarak değerlendirildiğinde, radyometrik ölçümlerin başlangıcından 16 . haftaya kadar uygulamalar arası interaksiyonda herhangi bir fark belirlenmezken, bu haftadan itibaren spektrumun mavi dalga boyundaki yansıma düzeyi konular arasında farklılık göstermeye başlamıştır. Deneme sonunda en yüksek yansıma seviyesi yani en az enerji kullanımı düzeyi $\mathrm{S}_{4}$ uygulamasında belirlenirken $S_{1}, S_{2}$ ve $S_{3}$ uygulamaları arasinda önemli bir farklılık belirlenmemiştir. Sözkonusu uygulamaların tamamı istatistiksel olarak kontrol $\left(\mathrm{S}_{0}\right)$ uygulamasından daha yüksek yansıma değeri göstermiştir. Nitekim, spekturmun mavi dalga boyu bölgesinde enerji kullanımı kontrol uygulamasında en fazla düzeye ulaşmış olup, yansımada azalma şeklinde kendini göstermiştir (Şekil 1a).

Spektrumun yeşil dalga boyu bölgesinde ise, spektroradyometrik ölçümlerin başlangıcından 13 . haftaya kadar uygulamalar arası interaksiyonda herhangi bir farklılık belirlenmemiș olup, bu haftadan itibaren konular arası farklılıklar ortaya çıkmaya başlamıştır. Spektrumun yeşil dalga boyundaki yansıma düzeyi istatistiksel olarak benzer şekilde $\mathrm{S}_{2}, \mathrm{~S}_{3}$ ve $\mathrm{S}_{4}$ uygulamalarının yansıma düzeylerinde hizla artarak, dönem sonunda en yüksek seviyeye, yani enerji kullanımları en az düzeye ulaşmıştır. Uygulamaların tamamı istatistiksel olarak kontrol uygulamasından daha yüksek yansıma değeri göstermiş olup, elektromanyetik spektrumun bu dalga boyu bölgesindeki enerji kullanımı mavi dalgaboyu bölgesinde olduğu gibi kontrol uygulamasında da en yüksek düzeye ulaşmıştır. Craig \& Shih (1998) yaptıkları bir çalışmada da, tuzluluk etkisinin elektromanyetik spektrumun 700 $\mathrm{nm}$ civarında ve 500-600 nm'deki yeşil-sarı spektral bölgede ortaya çıktığı ve bu bölgedeki yansımada önemli bir artışla kendini gösterdiğini belirtmişlerdir (Şekil 1b).

Elektromanyetik spektrumun klorofil absorbsiyon bölgelerinden birisi olan kırmızı dalga boyu bölgesinde ise, yetiştirme periyodunun 16. haftasına kadar uygulamalar arası interaksiyonlarda herhangi bir farklılık görülmezken; bu haftadan itibaren konular arasında farklılıklar ortaya çıkmış ve deneme sonunda yansıma düzeyi en yüksek $\mathrm{S}_{2}, \mathrm{~S}_{3}$ ve $\mathrm{S}_{4}$ uygulamalarında, en düşük ise kontrol konusunda belirlenmiştir (Şekil 1c).

Çalışmanın bir diğer aşamasında ise, elektromanyetik spektrumun farklı dalga boyu bölgesinde her bir uygulama ayrı ayrı incelenmiştir. Böylelikle, domates bitkisinin yetiştirme periyodu boyunca ortaya çıkan stres durumunun bitkideki enerji kullanımı üzerine etkisinin hangi haftada belirleyici olduğu istatistiksel olarak belirlenmeye çalışılmıştır. Genel olarak, bitki gelişmesine paralel olarak bitki yapraklarından meydana gelen yansımalarda artışlar meydana gelmiş ve gelişme dönemi ile spektrumun mavi, yeşil, kırmızı ve yakın kızı̈ötesi dalgaboyları arasında \% 1 düzeyinde önemli istatistiksel farklılıklar belirlenmiştir (Çizelge 2).

Spektrumun mavi dalga boyu bölgesinde bitkinin gelişim periyodu süresince kontrol konusunun yansıma düzeyi önemli bir farklılık göstermezken, sözkonusu farklılık $S_{1}$ ve $S_{3}$ konularında 20. ve $S_{2}$ konusunda 18. ve $S_{4}$ uygulamasinda ise 16 . haftada görülmeye başlanmıştır (Şekil 1a). Bu bulguya göre elektromanyetik spektrumun mavi dalga boyu bölgesinde, tuzlu sulama suyunun enerji kullanımına etkisinin belirlenmesinde $S_{1}, S_{2}$ ve $S_{3}$ uygulamalarının yeterli olmadığı, $\mathrm{S}_{4}$ uygulamasının ise 16 . haftada belirleyici olduğu sonucuna ulaşılmıştır.

Spektrumun yeşil dalga boyu bölgesinde, ortaya çıkan stres durumunun bitkideki enerji kullanımı üzerine etkisi, $S_{1}$ ve $S_{2}$ uygulamarında 8 . haftada, $S_{3}$ ve $S_{4}$ uygulamalarında ise 14. haftada kendini göstermiştir. Bununla birlikte kontrol uygulamasında önemli bir değişim gözlenmemiştir (Şekil 1b). 

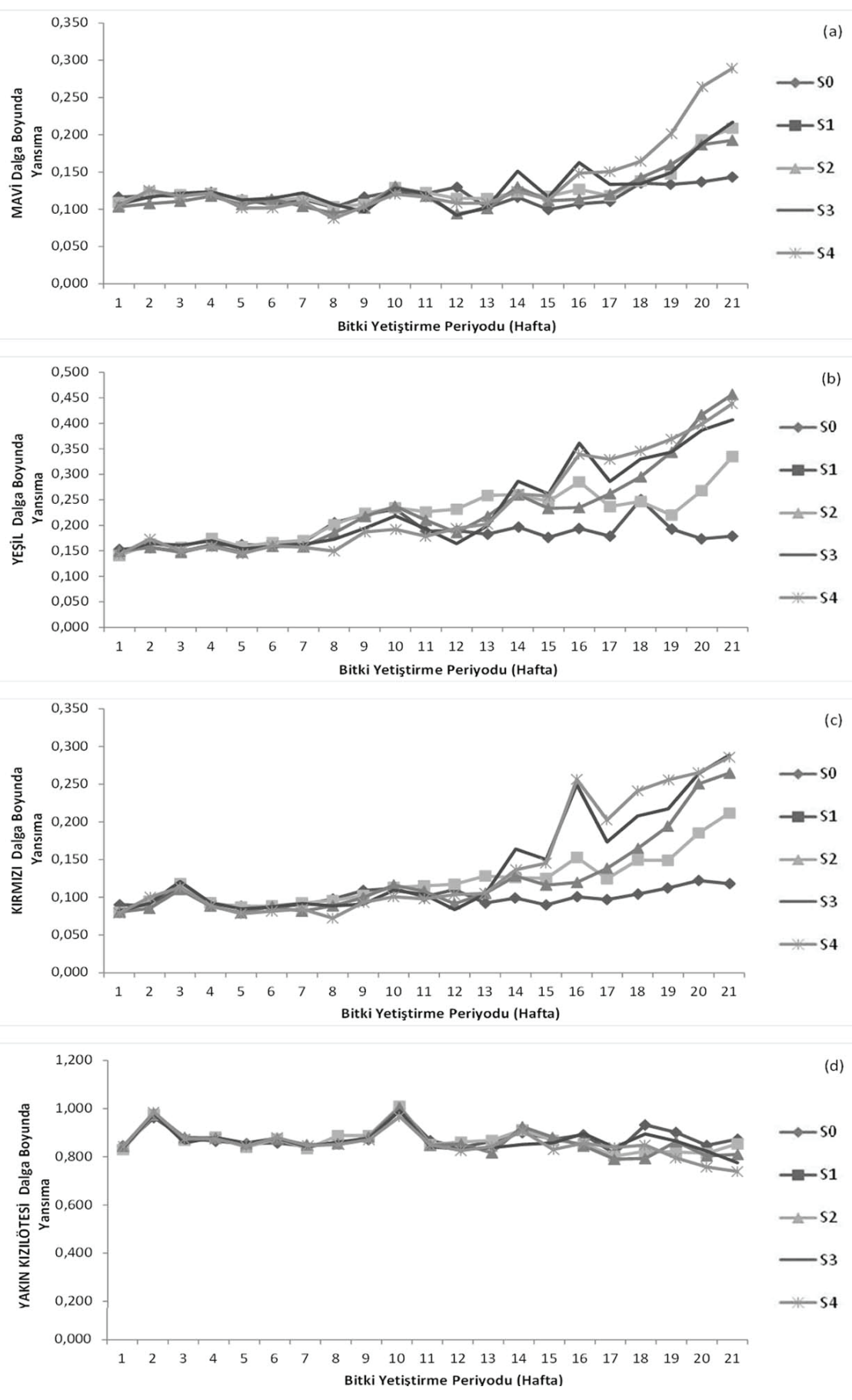

Şekil 1- Bitki yetiştirme periyodu boyunca uygulamalar arasındaki ilişkiler

Figure 1-Relationships between applications during the growing periods 
Bitkinin kırmızı dalga boyundaki enerji kullanımı her bir uygulama için ayrı değerlendirildiğinde, $\mathrm{S}_{1}$, $\mathrm{S}_{2}, \mathrm{~S}_{3}$ ve $\mathrm{S}_{4}$ konularında sirasiyla 16,18 ., 14. ve 9. haftada yansıma değerinde önemli düzeylerde farklılıkların başladığı ortaya çıkmıştır. Diğer dalga boylarında olduğu gibi kontrol uygulamasında da istatistiksel olarak herhangi bir değişim belirlenmemiştir (Şekil 1c).

Bitkilerin stres koşullarının belirlenmesinde en belirleyici dalga boyu aralığının elektromanyetik spektrumun yakın kızı̈ötesi bölgesi olduğu pek çok araştırmacı tarafından ifade edilmektedir (Slaton et al 2001; Leone et al 2007). Domates bitkisine uygulanan tuzlu sulama suyu uygulamaları ve bu uygulamalar neticesinde ortaya çıkan bitki stres koşullarının belirlenmesi amacı ile yakın kızılötesi dalgaboyu ile hem tuz uygulamaları arasinda ve hem de bitki yetiştirme periyodu boyunca yansıma miktarlarındaki değişim ve tepki istatistiksel olarak değerlendirilmiştir. Analiz sonuçlarına göre, spektrumun bu dalga boyu bölgesinde genel olarak anlamsız yansıma değişimleri tespit edilmiş olup sadece gelişim periyodu boyunca her bir uygulama için elde edilen yansıma değerlerinin ortalamaları arasındaki ilişki sorgulanabilmiştir. $\mathrm{Bu}$ açıdan değerlendirildiğinde en yüksek yansıma değeri kontrol, $\mathrm{S}_{1}, \mathrm{~S}_{2}$ ve $\mathrm{S}_{3}$ uygulamalarında en düşük ise $\mathrm{S}_{4}$ konusunda belirlenmiştir (Şekil 1d). Tuzluluk artışına bağlı olarak yakın kızılötesi dalgaboyunda yansıma değerindeki bu düşüş pek çok literatürle paralellik göstermektedir (Bhatt et al 2004; Eldiery et al 2005; Duran 2007). Çalışmadan elde edilen sonuçlar, domates bitkisinin tuzlu sulama suyundan kaynaklanan stres koşullarının belirlenmesinde infrared bölgenin belirleyici olduğunu ancak stres koşullarının ortaya çıkma dönemlerini belirlemede yeterli olmadığını göstermektedir. Bu nedenle bu çalışmada tuz stresinin belirlenmesinde farklı indeks hesaplamaları yapılmış ve bu konu üzerinde yoğunlaşılmıştır.

Bant oranlama indeksi (VI), daha önce de belirtildiği gibi bitkinin stres koşullarının belirlenmesinde oldukça önemlidir. $\mathrm{Bu}$ indeksle hesaplanan değerin yüksek olması bitkinin sağlıklı olduğunu, düşük olması ise bitkinin stres altında olduğunu göstermektedir (Oscar 1998; Çetin et al 2003). Araştırmada, farklı düzeylerdeki tuz uygulamalarının bant oranlama indeksi üzerine etkilerine ilişkin hesaplanan varyans analiz sonuçları, istatistiksel olarak \% 1 düzeyinde önemli bulunmuştur. Analiz sonuçlarına göre, genel olarak 12. haftaya kadar uygulamalar arasinda herhangi bir farklılık gözlenmezken bu haftadan itibaren stres koşulu arttıkça kırmızı eşik değerinde de azalma meydana gelmiştir (Şekil 2a).

Yetiştirme periyodu boyunca uygulamalardaki farklılıklar her bir uygulama için ayrı ayrı değerlendirildiğinde ise, kontrol uygulamasında istatistiksel olarak önemli düzeyde herhangi bir fark görülmezken, $S_{1}$ ve $S_{2}$ uygulamalarında 13., $\mathrm{S}_{3}$ uygulamasinda 11. ve $\mathrm{S}_{4}$ uygulamasinda ise 9. haftadan itibaren kırmızı eşik değerlerinde önemli azalmalar belirlenmiştir (Şekil 2a). Elde edilen bulgular diğer araştırmacıların sonuçlarıyla paralellik göstermektedir.

Normalize edilmiş bitki indeksi (NDVI) için gerçekleştirilen varyans analizleri sonuçlarına göre ise, tuz uygulaması, dönem ve bunların interaksiyonlarının NDVI değerleri üzerine etkileri istatistiksel olarak \% 1 düzeyinde önemli bulunmuştur. $\mathrm{Bu}$ kapsamda hesaplanan NDVI değerleri ile uygulamalar arasındaki ilişkiler istatistiksel olarak değerlendirilmiş ve 14. haftaya kadar uygulamalar arasında herhangi bir fark görülmemiştir. Deneme sonunda en yüksek NDVI değeri kontrol, en düşük ise $\mathrm{S}_{3}$ ve $\mathrm{S}_{4}$ uygulamalarında belirlenmiştir. Her bir uygulama için elde edilen ortalama NDVI değerleri arasındaki ilişkiler analiz edildiğinde $S_{1}$ ve $S_{2}$ uygulamaları ile $\mathrm{S}_{3}$ ve $\mathrm{S}_{4}$ uygulamaları kendi aralarında benzerlikler göstermiştir. Stres koşullarının tespiti amac1 ile hesaplanan NDVI değerleri, yetiştirme periyodu boyunca her bir deneme konusu için ayrı değerlendirildiğinde ise, tuzlu sulma suyunun $\mathrm{S}_{1}$ düzeyindeki NDVI değerlerinde 15., $\mathrm{S}_{2}$ uygulamasında 17., $\mathrm{S}_{3}$ ve $\mathrm{S}_{4}$ uygulamalarında ise 14 . haftadan itibaren düşüşler gözlemlenmiştir (Şekil $2 b)$. 

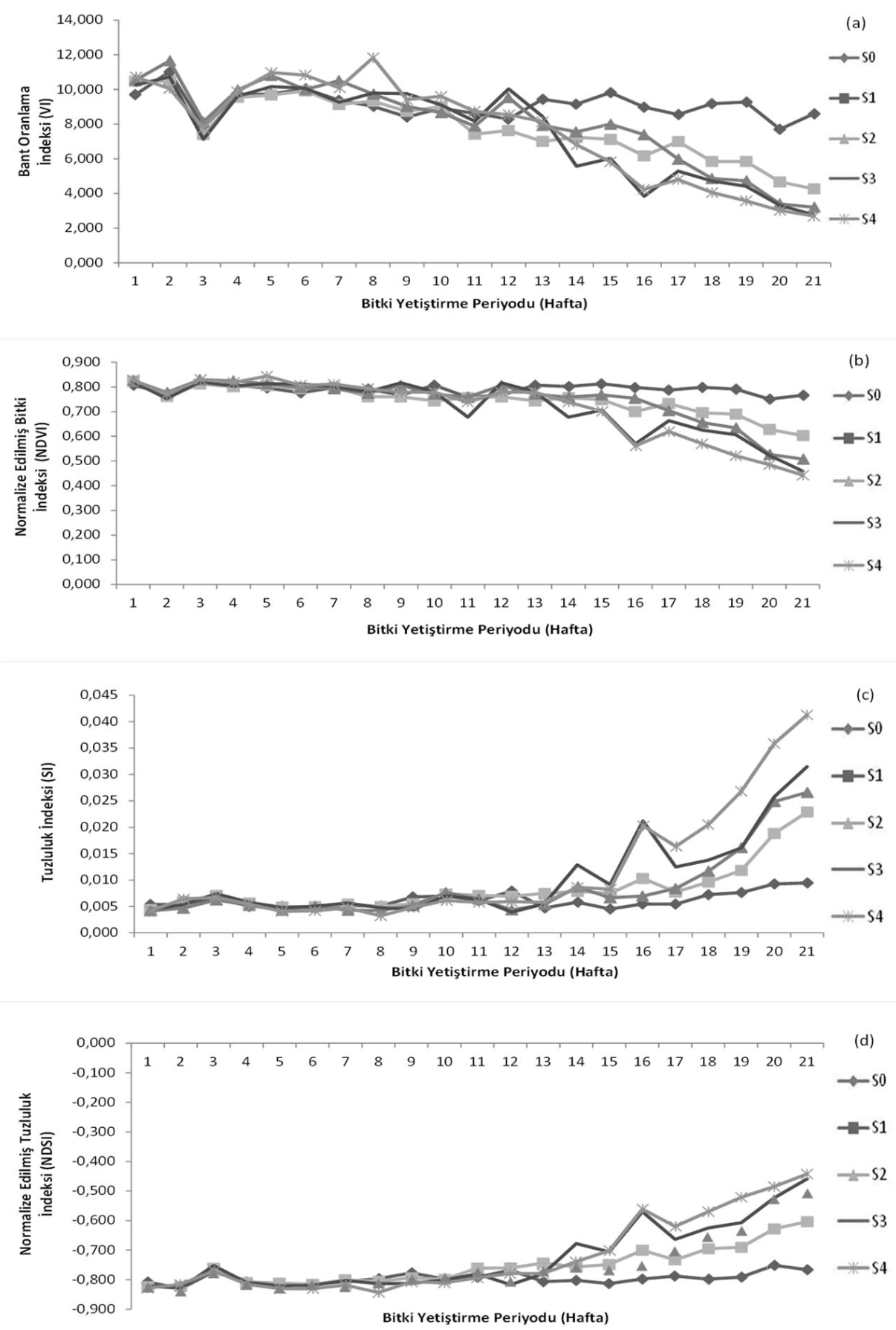

Şekil 2- Tuz uygulamalarının ve dönemlerin indeksler üzerine etkileri

Figure 2- The effects of salt applications and periods on indexes 
Yapılan literatür araştırmalarında topraktaki tuzluluk düzeyinin belirlenmesinde birtakım tuzluluk indeks hesaplamalarının kullanıldığı belirlenmiştir. Bunlar, Tuzluluk İndeksi (SI) ve Normalize Edilmiş Tuzluluk İndeksi (NDSI) olarak adlandırılan indekslerdir (Allbed \& Kumar 2013). Khan \& Sato (2001) yaptıkları bir araştırmada, çeşitli bantların kombinasyonları ile oluşturulan indislerin genellikle bitki sağlığı, ürün değerlendirmesi ve arazi kullanım değişikliği gibi konuların belirlenmesi için olduğunu, buna karşın tuzdan etkilenen alanları belirlemede bu indislerin yetersiz kaldığını bildirmişlerdir. Her ne kadar bu indeksler toprak tuzluluğu ile doğrudan ilişkili olmasa da, çalışmanın bu aşamasında söz konusu bu indislerin domates bitkisinin tuz stresinden kaynaklanan enerji kullanımındaki değişimlerinin tespitinde kullanılabilirliği test edilmiştir.

$\mathrm{Bu}$ kapsamda, domates bitkisine yetiştirme periyodu boyunca devam eden farklı düzeylerdeki tuzlu sulama suyu uygulamalarının, SI ve NDSI değerleri üzerine etkilerine ilişkin varyans analiz sonuçlarına göre, farklı düzeylerdeki sulama uygulamaları, dönem ve bunların interaksiyonlarının SI ve NDSI değerleri üzerine etkileri istatistiksel olarak \% 1 düzeyinde önemli bulunmuştur. Çalışmada hesaplanan SI değerleri ile uygulamalar arasındaki ilişkiler istatistiksel olarak değerlendirildiğinde, 16. haftaya kadar uygulamalar arasında istatistiksel olarak herhangi bir farklılık belirlenmemiştir. Gelişim periyodunun 16 . haftasında $S_{3}$ ve $S_{4}$ uygulamaları diğer uygulamalardan ayrılarak artış göstermiştir. Uygulamaların tüm gelişim periyodu boyunca SI değerlerinin ortalamaları arasındaki ilişkiler analiz edildiğinde $S_{0}, S_{1}$ ve $S_{2}$ uygulamalarının istatistiksel olarak bir farklılık göstermediği $\mathrm{S}_{3}$ ve $\mathrm{S}_{4}$ uygulamalarının SI değerlerinin ise daha yüksek olduğu belirlenmiştir. Hesaplanan SI değerleri, bitki yetiştirme periyodu boyunca her bir deneme konusu için ayrı ayrı değerlendirildiğinde, tuzluluk indeksi değerlerinde kontrol konusunda herhangi bir farklılık belirlenmezken, $S_{1}$ ve $S_{2}$ uygulamalarında 18., $\mathrm{S}_{3}$ ve $\mathrm{S}_{4}$ uygulamalarında ise 16 . haftada artışların başladığı belirlenmiştir (Şekil 2c).
Aynı şekilde, hesaplanan NDSI değerleri ile uygulamalararasındakiilişkilerdeğerlendirildiğinde, yetiştirme periyodu boyunca tüm uygulamalar arasında 14. haftada farklılığın başladığ gözlenmiş olup, $\mathrm{S}_{1}$ ve $\mathrm{S}_{2}$ ile $\mathrm{S}_{3}$ ve $\mathrm{S}_{4}$ uygulamaları benzer ilişki göstermiş ve kontrol uygulamasından daha yüksek değerler almıştır. Bitki yetiştirme periyodu boyunca her bir deneme konusu için NDSI değerlerinin $\mathrm{S}_{1}$ ve $\mathrm{S}_{2}$ uygulamalarında istatistiksel açıdan 18., $\mathrm{S}_{3}$ ve $S_{4}$ uygulamalarında ise 16 . haftada farklılık göstermeye başladığı belirlenmiştir (Şekil 2d).

\section{Sonuçlar}

Elde edilen araştırma sonuçlarına göre, domates bitkisinin yetiştirme periyodu boyunca devam eden değişik tuzluluk düzeylerine sahip sulama suyu uygulamalarının, elektromanyetik spekturumun mavi, yeşil ve kırmızı dalga boyu aralıklarında enerji kullanımında azalmaya (yansımada artış) neden olduğu belirlenmiştir. Domates, bitkisi için spektrumun bu bölgesinde yansımada artış şeklinde elde edilen bulgular diğer araştırmalarla paralellik göstermektedir. Ayrıca, elde edilen bulgular, domates bitkisinin tüm uygulamalar ile gelişim periyodu buyunca verdiği ortalama yansıma değerlerinin, tuz konsantrasyonundaki değişime bağlı olarak elektomanyetik spektrumun mavi dalga boyu bölgesindeki enerji kullanımına etkisi, bitki gelişim periyodunun 16. haftasında, yeşil dalga boyu bölgesinde 13. haftasında, kırmızı dalga boyu bölgesinde 16. haftasında belirleyici olmuştur. Spektrumun yakın kızılötesi bölgesindeki yansıma düzeyindeki değişimler topluca değerlendirildiğinde ise bu bitki için anlamlı bir interaksiyon ortaya çıkmamıştır. Bitkinin tüm uygulamalar ile gelişim periyodu buyunca belirlenen indeks değerlerinin birlikte değerlendirilmesi neticesinde, farklı tuzluluk düzeylerine sahip sulama suyunun VI değerleri üzerine etkisinin yetiştirme periyodunun 12. haftasında, hesaplanan NDVI değerlerine 14. haftasında, SI değerine 16. haftasında ve NDSI değerine ise 14. haftasında belirleyici olduğu sonuçuna ulaşılmıştır. Araştırma sonuçları, bazı indeks değerlerinin her ne kadar toprak için geliştirildiği ifade edilse de, tuzdan kaynaklanan 
bitki stres koşullarının belirlenmesinde de kullanılabileceğini göstermektedir.

Sonuç olarak bu çalışma ile, uzaktan algılama tekniklerinin bir şekli olan yersel ölçüm teknikleri (spektroradyometre) kullanılarak yapılan yansıma ölçümlerinin, domates bitkisinde sulama suyu tuzluluğundan kaynaklanan stres durumunun tespitinde başarılı sonuçlar verdiği belirlenmiştir. Çalışma, tuzluluktan kaynaklanan bitki stres durumunun, bitki henüz strese girmeden önce tespit edilebileceğini göstermesi açısından önem taşımaktadır.

\section{Teşekkür}

Çalışmanın yapılmasında katkılarından dolayı Akdeniz Üniversitesi Bilimsel Araştırma Projeleri Koordinasyon Birimine teşekkür ederiz.

\section{Kaynaklar}

Allbed A \& Kumar L (2013). Soil salinity mapping and monitoring in arid and semi-arid regions using remote sensing technology: A review. Advances in Remote Sensing 2: 373-385

Ayers R S \& Westcot D W (1989). Water quality for agriculture. irrigation and drainage paper, Food and Agriculture Organization of the United Nations, 29, Rev. 1. Rome, 1-pp: 174

Ayyıldız M (1990). Sulama Suyu Kalitesi ve Tuzluluk Problemleri. Ankara Üniversitesi, Ziraat Fakültesi Yayınları: 1196, Ders Kitabı: 344, Ankara

Bresler E \& Charter D L (1982). Saline and Sodic Soils. Principles Dynamics-Modelling. Springer Verlag, Berlin Heidelberg, New York., pp: 227

Büker C, Clevers J G P W \& Kuhbauch W (1992). Measuring the intensity of nitrogen fertilization of grassland by means of remote sensing. European "International Space Year Conference" Remote Sensing for Environmental Monitoring and Resource Management, 30 March-4 April, Munich, Germany

Bhatt C M, Singh R K, Litoria P K \& Sharma P K (2004). Use of remotely sensed data and GIS techniques for assessment of aterlogged and salt-affected area Tehsilwise in Muktsar district of Punjab. GSDI 7 Conference. January 30- February 6, 2004 Theme: Spatial Data Infrastructures for a Sustainable Future
Bangalor, India http:/gsdidocs.org/gsdiconf/GSDI-7/ papers/Pcmb.pdf (Erişim tarihi 15.12.2012)

Campbell J B (2006). Introduction to Remote Sensing. Fourth Edition The Guilford Publications, New York. pp: 6

CCRS (2003). Canada Centre of Remote Sensing. http:// www.ccrs.nrcan.gc.ca/http://www.crisp.nus. edu.sg/ research/tutorial/em.htm (Erişim tarihi 14.12.2012)

Craig J C \& Shih S F (1998). The spectral response of stress conditions in citrus trees: Development of methodology. Soil and Crop Science Society of Florida 57: 16-20

CRISP (2011). Principles on remote sensing. Centre for remote imaging, sensing \& processing. http://www. crisp.nus.edu.sg/ research/tutorial/em.htm (Erişim tarihi 14.12.2012)

Çakırlar H \& Topçuoğlu S F (1985). Stres terminolojisi. Çölleşen dünya ve Türkiye örneği. Sempozyum-7, 1317 Mayıs, Erzurum, s. 108-129

Çetin M, Baz İ, Kayzoğlu T \& Geymen A (2003). Çok zamanlı uydu görüntüleri ile açık maden ocaklarındaki yeryüzü değişiminin incelenmesi. 9. Türkiye Harita Bilimsel ve Teknik Kurultayl, 31 Mart-4 Nisan 2003, Ankara, s. 231-241

Duran C (2007). Uzaktan algilama teknikleri ile bitki örtüsü analizi. Doğa Dergisi 13: 45-67

Eldiery A A, Garcia L \& Reich R M (2005). Estimating soil salinity from remote sensing data in corn fields. http://hydrologydays.colostate.edu/Papers_2005/ Ahmed_paper.pdf (Erişim tarihi 29.12.2012)

FAO (1979). Yield response to water. Irrigation and Drainage Paper Rome 33: 115

Filella I \& Penuelas J (1994). The red edge pozition and shape as indicators of plant chlorophyl content, biomass and hydric status. International Journal of Remote Sensing 15(7): 1459-1470

Jackson R D (1984). Remote sensing of vegetation characteristics for farm management. Sixth in the SPIE Critical Reviews of Technology Series: Remote Sensing 475: 81-96

Jacquemoud S \& Ustin S I (2001). Leaf optical properties: A state of the art. Proc. 8th Int. Symp. "Phyisical Measurements and Signatures in Remote sensings", 8-12 Jan, France, pp: 223-232

James D W, Hanks R J \& Jurinak J J (1982). Modern Irrigated Soils. John Wiley and Sons Print., USA 
Khan N M \& Sato Y (2001). Monitoring hydro-salinity status and its impact in irrigated semi-arid areas using IRS-1B LISS-II data. Asian Journal of Geology 1(3): $63-73$

Köksal E S (2007). Sulama suyu yönteminde uzaktan algılama tekniklerinin kullanımı. OMÜ Ziraat Fakültesi Dergisi 22(3): 306-315

Leone A P, Menenti M, Buondonno A, Letizia A, Maffei C \& Sorrentino G (2007). A field experiment on spectrometry of crop response to soil salinity. Agricultural Water Management 89: 39-48

Maktav D \& Sunar F (1991). Uzaktan Algilama-Kantitatif Yaklaşım (Remote Sensing-A Quantitative Approach; Swain/Davis), Çeviri Kitap, Hürriyet Ofset, İstanbul

Merzlyak M N, Gitelson A A, Chivkunova O B, Solovchenko A E \& Pogosyan S I (2003). Application of reflectance spectroscopy for analysis of higer plant pigments. Russian Journal of Plant Physiology 50: 704-710

NASA (2003). National aeronautics and space administration. http://daac.gsfc.nasa.gov/CAMPAIN DOCS/(Erişim tarihi 5.12.2012)
Oscar V (1998). Vegetation. http://137.224.135.82/cgi/ projects/bcrs/multisensor/ report1/ 4.htm\#f_4_1_1. (Erişim tarihi 10.12.2012)

Rahman S, Vance G F \& Munn L C (1994). Detecting salinity and soil nutrient deficiencies uusing SPOT satellite data. Journal of Soil Science 158: 31-39

Rees W G (1990). Remote Sensing Physical Principles of Remote Sensing. Cambridge University Press. Cambridge, United Kingdom

Robinson S P, Downton W J S \& Millhouse J A (1983). Photosynthesis and ion content of leaves and isolated chloroplasts in relation to ionic compartmentation in leaves. Agricultural Biochemistry and Biology 228: 197-206

Sharma D A (1980). Effect of using saline water to supplement canal water irrigation on the crop growth of rice. Current Agriculture 4: 79-82

Slaton M R, Hunt E R \& Smith W K (2001). Estimating near infrared leaf reflectance from leaf structural characteristics. American Journal of Botany 88(2): 278-284

White K (1998). Remote Sensing. Progress in Physical Geography 22(1): 95-102 